\title{
EL ESTATUTOO DE LOS TRABAJADORES ESPAÑOL EN EL CINCUENTA ANIVERSARIO DEL ITALIANO
}

\author{
Francisco Pérez de los Cobos Orinuel \\ Catedrático de Derecho del Trabajo y de la Seguridad Social \\ Facultad de Derecho. Universidad Complutense \\ Presidente Emérito del Tribunal Constitucional \\ franciscoperezdeloscobos@der.ucm.es
}

\section{RESUMEN}

Aprovechando la coincidencia temporal entre los aniversarios del Estatuto de los Trabajadores español y su homólogo italiano, el autor hace una reflexión sobre el muy distinto significado y contenido de ambas normas. El Estatuto español obedece a un mandato constitucional e históricamente es un producto de la transición democrática, cuyos valores el autor reivindica para el momento que viene.

Palabras clave: Constitución, Estatuto de los Trabajadores, contrato de trabajo, negociación colectiva, reforma laboral.

\section{ABSTRACT}

On the occasion of the anniversary of Spanish and Italian Statutes, the writer reflects on the differences in meaning and content in between them. Spanish statute relates to a constitutional act which is a historical consequence of democratic transition, claimed by the writer for the coming times.

Keywords: Constitution, Workers Statute, Job Contract, Collective Negotiation, Labour Reforms.

\section{ZUSAMMENFASSUNG}

Der Autor nutzt die Gleichzeitigkeit zwischen den Jabrestagen des spanischen Arbeiterstatuts und seines italienischen Gegenstücks, um über die sebr unterschiedliche Bedeutung und den Inbalt der beiden Normen nachzudenken. Das spanische Statut gehorcht einem verfassungsmäßigen Auftrag und ist historisch geseben ein Produkt der Epoche des Übergangs zur Demokratie, dessen Werte der Autor für die Zukunft einfordert.

Schlüsselwörter: Verfassung, Arbeitnehmerstatut, Arbeitsvertrag, Tarifverhandlungen, Arbeitsreform. 
SUMARIO: I. INTRODUCCIÓN.-II. LA PREVISIÓN CONSTITUCIONAL DE UN ESTATUTO DE LOS TRABAJADORES.-III. EL ESTATUTO DE LOS TRABAJADORES DE 1980.-IV. UNA NORMA INCENSANTEMENTE REFORMADA.-V. ¿HACIA UN NUEVO ESTATUTO DE LOS TRABAJADORES?-VI. BIBLIOGRAFÍA.

\section{INTRODUCCIÓN}

Pese a la idéntica denominación y al lugar central que ambas normas ocupan en nuestros respectivos ordenamientos laborales, lo primero que necesariamente debe ponerse de relieve en este coincidente aniversario del Statuto dei Lavoratori italiano (50 aniversario) y del Estatuto de los Trabajadores español (40 aniversario) es que nos encontramos ante dos normas distantes y distintas, cualquiera que sea el punto de vista desde el que se las mire. En realidad, más allá de las mencionadas similitudes, ninguna otra destacada característica las hermana: ni el bumus cultural y político que está en la génesis del Estatuto italiano ${ }^{1}$ subyace al español, que responde exactamente al contexto de nuestra transición democrática, ni los proyectos de política del Derecho que animan a una y otra norma son similares, ni, en fin, la morfología y contenidos de ambas regulaciones resultan comparables.

El propósito de este breve ensayo es el de justificar esta afirmación de partida, centrándome en explicar al lector cuál fue la génesis de nuestro texto legal, qué papel-en sus diferentes versiones- ha desempeñado y desempeña en nuestro sistema de relaciones laborales, y qué augurios sobre su futuro se barajan.

\section{LA PREVISIÓN CONSTITUCIONAL DE UN ESTATUTO DE LOS TRABAJADORES}

La redacción del Estatuto de los Trabajadores por el legislador es, de acuerdo con lo establecido en el art. 35 de nuestro texto constitucional, una obligación del legislador. En efecto, la Constitución española de 1978,

${ }^{1}$ Sobre la génesis y significado de la norma italiana, vid. U. Romagnoli, Il lavoro in Italia. Un giurista racconta, Bolonia, Il Mulino, 1995, pp. 155 y ss. Sobre su vigencia, vid. U. Romagnoli, «Tornare allo Statuto», Lavoro e diritto, núm. 1 (2010), pp. 39-48; asî como los ensayos de M. NAPOLI, «Lo Statuto dei lavoratori ha quarant'anni, ben portati», y L. Zoppoli, «Le rughe dello Statuti e le maschere del futuro», ambos en Lavoro e diritto, núm. 1 (2010), pp. 123-138 y 59-73 respectivamente. 
cuya aprobación supuso un verdadero punto de inflexión en nuestro proceso de transición democrática, al regular en su título I los derechos y deberes fundamentales introdujo en la sección 2. ${ }^{a}$ del capítulo I, concretamente en el art. 35.2, la siguiente previsión: «La Ley regulará un estatuto de los trabajadores».

Este precepto constitucional fue objeto de un parco debate parlamentario por las Cortes constituyentes. En parecidos términos a los hoy vigentes aparece ya en el texto del anteproyecto de texto constitucional, concretamente en el art. 30; precepto que, junto con el art. 31, pretendía regular el conjunto de los derechos laborales en la Constitución. El principal cambio que durante el proceso de elaboración del texto constitucional se produjo al respecto consistió precisamente en el desgajamiento de esta regulación conjunta de los derechos constitucionales laborales en favor de una regulación diversificada en la que, de una parte, los derechos de libertad sindical y huelga pasan a ser reconocidos como derechos fundamentales en la sección $1 .^{a}$ del capítulo II del título I, haciéndolos así merecedores del máximo nivel de protección constitucional, mientras que, de otra, los derechos de negociación colectiva, derecho a adoptar medidas de conflicto colectivos, el deber de trabajar y el derecho al trabajo, así como los derechos a la libre elección de profesión, a la promoción a través del trabajo, a una remuneración suficiente y la previsión de «un estatuto de los trabajadores», pasan a ubicarse en la sección 2. ${ }^{a}$ del mismo capítulo relativa a «los derechos y deberes de los ciudadanos», lo que supuso dotarlos de un menor nivel de garantías.

Será precisamente esta ubicación del precepto que nos ocupa, más allá de la terminología utilizada en su escueto tenor, lo que resultó determinante a la hora de interpretarlo y desarrollarlo, pues aunque la izquierda parlamentaria invocó el precedente italiano para pretender un desarrollo del precepto constitucional que lo asemejase, por parte del Gobierno y de la mayoría que lo sustentaba se alegaron poderosas razones jurídicas, amén de la oportunidad política, que postulaban en favor de una lectura distinta del precepto, que finalmente se impuso. Estas razones jurídicas fueron en síntesis las siguientes:

1. Como consecuencia de la diversificación reguladora aludida, tanto la regulación legal de la libertad sindical como la de los demás derechos fundamentales y libertades públicas (los de la sección 1. ${ }^{a}$ del capítulo II del título I), es decir, los contenidos fundamentales del Statuto dei Lavoratori, quedaron reservados a la ley orgánica, para cuya aprobación la 
Constitución requiere la mayoría absoluta del Congreso en una votación final sobre el conjunto del proyecto (art. 81 ET). Por el contrario, la ley a la que alude el art. 35.2 de la Constitución, que regulará un estatuto de los trabajadores, es una ley ordinaria, lo que, en principio, venía a denotar un contenido distinto.

2. $\quad$ El término «estatuto», sólidamente arraigado en nuestra tradición jurídica, es utilizado por el constituyente en numerosas ocasiones, precisamente para aludir a una regulación que establece los derechos y deberes y las reglas de gobierno de quienes pertenecen a un determinado colectivo profesional o cuerpo. Así, la Constitución se refiere, por ejemplo, al estatuto de los funcionarios públicos (art. 103.3), los estatutos de las Fuerzas y Cuerpos de Seguridad (art. 104.2), el estatuto jurídico de los jueces y magistrados de carrera (art. 122.1), el estatuto orgánico del Ministerio Fiscal (art. 124.3) o el estatuto de los miembros del Tribunal Constitucional (art. 165.1). Una lectura sistemática del precepto constitucional en relación con estos otros preceptos llama mutatis mutandi a una norma de contenido similar, es decir, a una ley que regule el régimen jurídico al que están sujetos los trabajadores.

3..$^{\circ}$ Se ha destacado en la literalidad del precepto la utilización del artículo indefinido «un» («la ley regulará un estatuto de los trabajadores»), que viene a reforzar su lectura plural y el margen de discrecionalidad que se reconoce al legislador en su desarrollo. El constituyente no prefigura el contenido del futuro estatuto que contempla - no puede, por tanto, pretenderse que su contenido sea semejante al italiano-, sino que a tal efecto remite a la libertad de configuración del legislador.

4. ${ }^{\circ}$ La lectura conjunta, en fin, de la previsión que glosamos con el apartado primero del precepto ofrecería significativos indicios sobre el contenido posible del estatuto en cuestión: derecho al trabajo, a la libre elección de profesión u oficio, a la promoción a través del trabajo y a una remuneración suficiente, sin que en ningún caso pueda hacerse discriminación por razón de sexo. El párrafo segundo se referiría al desarrollo y garantía de los derechos contemplados en el primero $^{2}$; interpretación que avalaba la propia génesis del precepto.

Al margen de estas razones jurídico-constitucionales, hubo razones políticas de peso que explican los contenidos que finalmente tuvo el Estatuto. Estas fueron fundamentalmente, en primer lugar, la necesidad de

2 M. C. Palomeque López, «Estatuto de los Trabajadores», en AAVV, Enciclopedia Laboral Básica «Alfredo Montoya Melgar», Madrid, Civitas, 2009, p. 617. 
reformar en sentido democratizador — es la primera norma laboral que desarrolla la nueva Constitución-y liberalizador —nace en plena crisis económica de los setenta- el modelo de relaciones de trabajo heredado del franquismo y, en segundo lugar, la de canalizar la representación colectiva de los intereses de los trabajadores y dar carta de naturaleza a un sistema de negociación colectiva democrático. Tanto para hacer frente a la situación de crisis económica que atravesaba el país como para afrontar la creciente conflictividad social, esta era la norma que urgía. La situación parlamentaria del entonces partido gobernante, la Unión de Centro Democrático, que gozaba de una mayoría parlamentaria suficiente pero no absoluta, también aconsejaba practicar la vía de la ley ordinaria prevista en el art. 35.2 CE y eludir para el Estatuto cualesquiera contenidos que requirieran de una ley orgánica.

\section{EL ESTATUTO DE LOS TRABAJADORES DE 1980}

Desde esta lectura del art. 35.2 de la Constitución ${ }^{3}$ fue elaborado el proyecto de ley del Estatuto de los Trabajadores que sería presentado al Congreso de Diputados. Un proyecto cuya Exposición de Motivos, luego suprimida durante la tramitación parlamentaria de la norma, ligaba claramente la nueva norma al nuevo marco constitucional: «La promulgación de la Constitución como norma jurídica primaria de nuestra sociedad afecta de un modo claro y directo a las relaciones de trabajo tanto a nivel individual como colectivo. El nuevo modelo político precisa, por pura coherencia, de un nuevo modelo laboral».

${ }^{3}$ La Exposición de Motivos del proyecto, que desaparecería durante su tramitación parlamentaria a instancia del Grupo Parlamentario Comunista, decía al respecto lo siguiente: «El art. 35.2 de la Constitución dispone que se regulará por ley un estatuto de los trabajadores. El término estatuto, de acuerdo con nuestra tradición histórica, supone, principalmente, la articulación de la situación jurídica de una pluralidad determinada de sujetos jurídicos y, por ende, de sus derechos y deberes. En tal sentido se pronuncia la Constitución, pues de ella se desprende, sin duda alguna, que el Estatuto de los Trabajadores es la norma estatal que establece y garantiza los derechos y deberes de los trabajadores por cuenta ajena». «La Constitución — seguía el texto- precisa con máxima claridad su rango normativo, ámbito personal y contenido. Se trata de una ley ordinaria (arts. 35.2, 51.1 y 149.1.7. ${ }^{\circ}$ ); su ámbito personal queda limitado por exclusión a los trabajadores por cuenta ajena (y) su contenido respeta al de las futuras leyes sobre la libertad sindical y de las asociaciones de empresarios y sindicatos de trabajadores (art. 28.1 y 7), así como sobre el derecho de huelga (art. 28.2), una y otra de naturaleza especial por su carácter orgánico». Cfr. J. A. SAGARDOy BengoecheA, «Pre e intrahistoria del Estatuto de los Trabajadores», Revista Española de Derecho del Trabajo, núm. 100 (2000), p. 33. 
El texto presentado ante las Cortes tenía ciento cinco artículos, agrupados en cuatro títulos referidos, respectivamente, a la relación individual de trabajo (título I), a los derechos de representación colectiva y de reunión de los trabajadores en la empresa (título II), a la negociación y a los convenios colectivos de trabajo (título III) y a los conflictos colectivos de trabajo (título IV). De estos cuatro títulos el que resultaba más problemático era el cuarto, pues sobre la base de que la Constitución Española regula de forma diferenciada el derecho de huelga (art. 28), para cuya regulación requiere de una ley orgánica, y el derecho a adoptar medidas de conflicto colectivo (art. 37.2), para cuyo desarrollo basta una ley ordinaria, intentaba la difícil e inviable operación de regular los conflictos de trabajo sin regular el derecho de huelga. Por ello, finalmente la comisión de trabajo del Congreso de los Diputados decidió, con buen criterio, suprimir del proyecto su último título.

¿Cuál fue el «nuevo modelo laboral» que el proyecto incorporaba y proponía a la sociedad española? Visto con distancia, resultó ser un pragmático e inteligente compromiso entre las exigencias constitucionales de reconocimiento de los derechos colectivos de los trabajadores, las primeras manifestaciones de requerimiento de flexibilidad laboral y el reciclaje de buena parte de la legislación heredada del franquismo. Esta propuesta de compromiso, que ya podía sobreentenderse de los términos del proyecto de estatuto presentado por el Gobierno a las Cortes, se reforzaría durante la tramitación parlamentaria del mismo, pues, como han recordado quienes vivieron el proceso en primera persona, el acuerdo se alimentó a través de sendas vías de negociación, abiertas en paralelo y que se fertilizaron recíprocamente. De una parte, la negociación abierta entre la patronal española, la Confederación Española de Organizaciones Empresariales, y la Unión General de Trabajadores, el sindicato socialista - Comisiones Obreras finalmente se autoexcluyó-, que rubricaron el primer gran pacto social entre interlocutores sociales de la etapa democrática, el llamado «Acuerdo Básico Interconfederal», que determinaría — aunque no solo- el contenido del título III de la nueva norma. De otra, una intensa negociación durante la tramitación parlamentaria del proyecto entre el partido del Gobierno, la Unión de Centro Democrático, y el principal partido de la oposición, el Partido Socialista Obrero Español, no así el grupo comunista que, al decir de Vida Soria, «mantuvo una actitud furibunda en contra del Estatuto» ${ }^{4}$. El consenso en la

\footnotetext{
${ }^{4}$ J. VIDA SORIA, «Vilanos del Estatuto de los Trabajadores (sobre su génesis, significado, evolución y su desaparición)», en J. M. Goerlich Peset (coord.), Comentarios al Estatuto de los Trabajadores. Libro homenaje a Tomás Sala Franco, Valencia, Tirant lo Blanch, 2016, p. 35.
} 
elaboración del Estatuto, que al decir de sus protagonistas abarcó su texto entero ${ }^{5}$, vino a ser una suerte de prolongación del consenso que rigió el proceso de elaboración de la Constitución Española de 1978.

Un somero repaso a los tres títulos de la nueva norma [Ley 8/1980, de 10 de marzo, del Estatuto de los Trabajadores (BOE de 14 de marzo)] permite destacar lo siguiente:

1. ${ }^{\circ} \quad$ Por lo que se refiere a la regulación de la relación individual de trabajo, el nuevo texto fue básicamente un reciclaje de la regulación franquista previa ${ }^{6}$, despojándola eso sí de elementos corporativistas, al que se añadió un escueto catálogo de derechos y deberes de los trabajadores ${ }^{7}$, desde luego no parangonable al Estatuto italiano, cuya función de tutela de los derechos fundamentales de los trabajadores en el trabajo debería ser cubierta básicamente por el Tribunal Constitucional a través de su jurisprudencia ${ }^{8}$. Las tímidas reformas materiales introducidas en la regulación del contrato de trabajo lo fueron en sentido liberalizador, pues, en general, se asumió la idea de que el reconocimiento de los derechos colectivos de los trabajadores debía compensarse menguando el hipergarantismo que en la regulación de la relación individual de trabajo caracterizó al último franquismo. Así, por ejemplo, en materia de contratación, aunque se mantuvo expresamente la prioridad por el contrato de duración indefinida, en paralelo se previó la prórroga de los contratos temporales en atención a la situación del mercado de trabajo y a la evolución del empleo, se insistió en las medidas incentivadoras de la contratación de personas con especiales dificultades de colocación y se dejó la puerta abierta a la posibilidad, luego decisiva en la evolución de nuestro mercado de trabajo, de utilizar la contratación temporal como medida de fomento del empleo ${ }^{9}$.

5 Ibid.

${ }^{6}$ Vid. in extenso F. SuÁREZ GonZÁlez, Las nuevas relaciones laborales y la Ley del Estatuto de los Trabajadores, Madrid, Pirámide, 1980.

7 En palabras de Vida Soria, «estos preceptos [los arts. 4 y 5 del texto legal] quisieron ser considerados las "huellas" (mejor se diría seudorestos) de un estatuto de los trabajadores entendido a la manera italiana». Vid. J. VIDA Soria, «Vilanos del Estatuto de los Trabajadores...», op. cit., p. 34 .

${ }^{8}$ El Tribunal se constituyó el 12 de julio de 1980, es decir, después de la entrada en vigor del Estatuto, y dictó su primera sentencia el 26 de enero de 1981. Desde entonces, la jurisprudencia del Tribunal ha desempeñado un papel fundamental en el reconocimiento y garantía de los derechos humanos en el trabajo, que en España no ha sido tanto función de la Ley —está prácticamente ausente del Estatuto- como de la Constitución misma en su aplicación interprivatos, afirmada por el Alto Tribunal desde la primera hora.

9 A. Montoya Melgar, «La Ley 43/2006 en el marco de las reformas laborales», en 
2. $\quad$ En la redacción del título II, relativo a la representación de los trabajadores en la empresa, se optó por incorporar al texto la representación unitaria anticipada durante la transición por el Real Decreto 3149/1977, de 6 de diciembre, sobre elección de representantes de los trabajadores en el seno de las empresas, esto es, las figuras de los comités de empresa y delegados de personal, a quienes se reconocieron competencias para negociar convenios colectivos de empresa y ámbito inferior. Por lo que se refiere a la representación sindical en la empresa, se prevé indirectamente su existencia (la representación unitaria se reconoce «sin perjuicio — se dice- de otras formas de representación», esto es, de las representaciones sindicales, a las que se legitima para negociar convenios «si las hubiere») ${ }^{10}$, pero se pospone su regulación al desarrollo del derecho de libertad sindical (art. 28.1), que se producirá más adelante con la Ley Orgánica 11/1985, de 2 de agosto, de Libertad Sindical. El doble canal de representación, unitario y sindical, de los trabajadores en la empresa data, por tanto, del Estatuto en su versión original. La asamblea de trabajadores fue regulada en términos restrictivos y formalizados para atajar el asamblerismo imperante en aquel momento de efervescencia social.

3. En lo que atañe al título III, la opción de política del Derecho más destacable, amén del amplio reconocimiento de la autonomía colectiva -ya expresamente realizado por el art. 37 de la Constitución-y de la consiguiente retracción del intervencionismo del Estado propio del régimen anterior, fue el mantenimiento del modelo de convenio colectivo preconstitucional de eficacia normativa y erga omnes, para lo cual la ley hubo de regular la «mayor representatividad» sindical ${ }^{11}$, sirviéndose al efecto de la representación obtenida al elegir a los representantes unitarios. Desde estos presupuestos, el convenio se configuró — lo que en buena medida explica la evolución normativa ulterior- como una auténtica ley profesio-

A. Montoya Melgar, J. M. Galiana Moreno, F. Cavas Martínez y A. Cámara Botía, Comentario a la reforma laboral de 2006, Madrid, Civitas, 2007, p. 24.

${ }^{10} \mathrm{La}$ introducción por esta vía del doble canal de representación fue uno de los caballos de batalla del grupo socialista durante el debate parlamentario.

${ }^{11}$ No faltó en la doctrina quien llamara la atención sobre el hecho de que regular la «mayor representatividad»y atribuir a quien la ostentase capacidad para suscribir convenios erga omnes suponía entrar de lleno en la regulación de la libertad sindical, para lo que la Constitución exigía una ley orgánica, pero el consenso entre los partidos mayoritarios viabilizó la reforma. Vid. E. BORRAJO DACRUZ, «Los convenios colectivos en el nuevo marco de las relaciones laborales (una introducción al Estatuto de los Trabajadores)», Revista de Estudios Sociales, núm. 1, 1979, pp. 37 y ss. 
nal que obliga con fuerza normativa a todos los empresarios y trabajadores comprendidos dentro de su ámbito de aplicación ${ }^{12}$.

El contraste entre los contenidos de la norma española y la de su homónima italiana no puede ser más elocuente. Como se ha apuntado, ambas respondieron a momentos, necesidades políticas y sociales y proyectos políticos muy diferentes, y por ello, sus contenidos fueron y son muy dispares. En un seminario europeo celebrado en octubre de 1979 en el Instituto de Estudios Sociales para hacer un balance del proyecto presentado, precisamente Gino Giugni, padre del Statuto dei lavoratori, consideró el texto español muy diferente del italiano, señalando que era más un pequeño código de trabajo que una ley sobre la protección de la libertad y la dignidad del trabajador en el lugar de trabajo. Pese a calificar el proyecto de «progresista», manifestó algunas reservas en particular respecto de la concesión de «demasiado protagonismo a la intervención del Estado en la relación colectiva de trabajo» ${ }^{13}$.

Con las limitaciones que se quiera, lo cierto es que el texto español respondió a las necesidades del momento y sirvió adecuadamente para lo que se le pedía, lo que expresivamente ha sido denominado «una voladura controlada del ordenamiento anterior de la dictadura franquista ${ }^{14}$. Desde entonces ha ocupado un lugar central en la regulación de nuestro sistema de relaciones laborales, hasta el punto que nadie le regatea la consideración de ser la norma básica que lo regula ${ }^{15}$. El hecho mismo de que, pese a las numerosas reformas que se han sucedido y a las que en seguida me referiré, siga vigente y ocupando tal lugar central dice suficientemente de su virtualidad normativa.

12 «En la actual situación laboral — había apuntado la Exposición de Motivos del proyecto- la eficacia erga omnes de los convenios colectivos puede ayudar a normalizar el proceso de negociación colectiva laboral».

${ }^{13}$ Citado por J. A. Sagardoy Bengoechea, «Pre e intrahistoria del Estatuto...», op. cit., p. 26.

${ }^{14}$ M. E. CASAS BAAMONDE, «La significación principal del Estatuto de los Trabajadores en el ordenamiento laboral constitucional», Trabajo y Derecho, núm. 63 (2020), versión electrónica, p. 7.

${ }_{15}$ Así, por ejemplo, Del Rey Guanter alude a su «centralidad y capacidad vertebradora» [S. Del Rey GuanteR, «Apología introductoria de la ley del Estatuto de los Trabajadores», en S. Del Rey Guanter (dir.), Estatuto de los Trabajadores. Comentado y con jurisprudencia, Madrid, La Ley, 2005, p. 18]; Casas Baamonde se refiere al mismo como la «ley central del ordenamiento laboral constitucional» (M. E. CASAS BAAMONDE, «La significación principal...», op. cit., pp. 10 y ss.), y Cruz Villalón habla de «norma referencial básica del ordenamiento laboral en nuestro país» [J. Cruz Villalón, «Hacia un nuevo Estatuto de los Trabajadores», Trabajo y Derecho, núm. 63 (2020), versión electrónica, p. 2]. 


\section{UNA NORMA INCESANTEMENTE REFORMADA}

A lo largo de su vigencia, el Estatuto de los Trabajadores ha sido reformado setenta y cuatro veces, setenta y dos si excluimos sendos decretos leyes, uno declarado inconstitucional y otro no convalidado por el Congreso de los Diputados ${ }^{16}$. Prácticamente, cada uno de los Gobiernos que, desde su entrada en vigor, se han sucedido no ha resistido la tentación de dejar su impronta en el Estatuto. Tan alto número de reformas, no obstante, viene a indicar que la gran mayoría de ellas fueron reformas menores de las que, por razones obvias, no vamos a dar cuenta en este breve ensayo. Pero junto a estas reformas menores ha habido al menos dos reformas de gran calado, auténticos hitos en la historia de la norma y en la evolución de nuestro sistema de relaciones laborales, a las que sí debo siquiera brevemente referirme. Si el texto del Estatuto vigente resulta ser muy distinto del inicial, en buena medida se debe al alcance de estas importantes reformas.

Vaya por delante que ambas reformas se pergeñan en el contexto de situaciones de crisis económicas profundas y ambas pretenden dar respuesta a dichas situaciones con recetas de carácter liberalizador. Pareciera el signo del Estatuto, que, como hemos visto, nació en el contexto de la crisis de los setenta y marcado por ella, y ha sido con posterioridad reformado incisivamente cuando nuevas situaciones de grave crisis menoscababan la economía y el empleo. Ambas se diseñaron por los respectivos Gobiernos - la primera por un Gobierno socialista, la segunda por un Gobierno del Partido Popular - al margen del diálogo social y suscitaron una fuerte contestación sindical. Desde el punto de vista formal, la primera reforma se instrumentó a través de sendas leyes, mientras que la segunda, siguiendo una deplorable y ya consolidada práctica respecto de nuestras reformas laborales, fue objeto de un real decreto-ley y tramitada con posterioridad, tras su convalidación parlamentaria, como proyecto de ley, lo que dio lugar a algunas modificaciones del texto inicial.

La primera gran reforma del Estatuto de los Trabajadores se lleva a cabo a través de las Leyes 10/1994, de 19 de mayo, sobre medidas urgentes de fomento de la ocupación, y 11/1994, de 19 de mayo, de reforma

16 Vid. un elenco de todas estas reformas en E. CABERo MorÁn, «La Ley del Estatuto de los Trabajadores cumple cuarenta años con tres versiones (1980, 1995 y 2015) y más de setenta reformas», Trabajo y Derecho, núm. 63 (2020), versión electrónica, p. 2. 
parcial del Estatuto de los Trabajadores y de otras leyes laborales; normas que modificaron buena parte del Estatuto, así como las pertinentes normas procesales y administrativas sancionadoras. Como ya se ha apuntado, el objetivo de la reforma fue dar respuesta a la situación económica y de empleo - el desempleo alcanzaba entonces la cota del 24,6\%- que atravesaba el país. A ella se aludió en las correspondientes Exposiciones de Motivos de ambos textos legales. La primera empezaba señalando que «la gravedad de la situación económica y su incidencia en el mercado de trabajo concede prioridad a la necesidad de acometer, de manera decidida y urgente, la reforma de las relaciones laborales con el objetivo de luchar contra el paro y potenciar nuestra capacidad generadora de empleo». En la segunda, si, de una parte, se hacía referencia a la necesidad de «mejora de la competitividad de las empresas» y a la garantía del «crecimiento económico», de otra se aludía al problema específicamente español de que dicho crecimiento, cuando lo había, tardaba en traducirse en significativa creación de empleo, todo ello para justificar la revisión del «marco institucional de las relaciones laborales».

La reforma de 1994, presentada bajo el emblema de la «adaptabilidad en el desarrollo de la relación laboral», fue singularmente profun$\mathrm{da}^{17}$ tanto por el número de preceptos reformados como por el alcance de las reformas. Las modificaciones abarcaron al conjunto del texto legal, sintéticamente:

1. ${ }^{a} \quad$ Por lo que se refiere al título I, relativo a la relación individual de trabajo, se produjo una significativa liberalización de la regulación. Se legalizaron las agencias privadas de colocación sin fines lucrativos y las empresas de trabajo temporal, y se flexibilizó la regulación de la relación individual de trabajo, en particular la de aquellas instituciones que permiten la adaptación de la empresa a los cambios económicos y productivos, a saber, la movilidad funcional, geográfica y las modificaciones sustanciales de las condiciones de trabajo — que permiten la flexibilidad interna en la empresa-, y el despido por causas económicas, técnicas, organizativas o productivas -instrumental a la llamada flexibilidad externa-. Tal flexibilización se tradujo en la eliminación de la autorización administrativa hasta entonces requerida para llevar a cabo las modificaciones sustanciales de condiciones de trabajo, los traslados y los despidos por causas empresariales que

${ }_{17}$ Un comentario completo de la misma en el número monográfico 17-18 de la revista Relaciones Laborales, de septiembre de 1994. Vid., asimismo, T. SALA FrAnCO, La reforma del mercado de trabajo, Valencia, CISS, 1994. 
no fueran colectivos y redundó, como es obvio, en un robustecimiento de las facultades de dirección de la empresa.

2. $\quad$ El título II del Estatuto, relativo a los «derechos de representación colectiva y de reunión de los trabajadores en las empresas», fue objeto de una reforma singular en el contexto de la general, pues en este ámbito el contenido de la ley nace de un acuerdo de «modificación de la normativa electoral y la representatividad sindical» suscrito por los sindicatos mayoritarios, acogido por el Gobierno y aceptado por el Parlamento. El propósito de la reforma en este punto también fue singular: evitar los problemas de confrontación sindical y litigiosidad en el control del resultado electoral que la regulación precedente del proceso electoral no conjuraba.

3. Por lo que se refiere a la negociación colectiva, los principales ejes de la reforma fueron tres. En primer lugar, se rebajaron las exigencias de legitimación negociadora empresarial, facilitando de esta suerte la actividad negociadora. En segundo lugar — este fue el verdadero eje de la reforma-, se llevó a cabo una significativa retracción de la ley en la regulación de numerosas instituciones jurídico-laborales, en particular en la ordenación del salario y la distribución de la jornada, abriendo en paralelo espacios de regulación a favor de la negociación colectiva ${ }^{18}$, a cuya regulación más dúctil se encomendó su regulación flexible. La cesión de la norma estatal en favor de la convencional se produjo utilizando fórmulas varias: desde la declaración del carácter dispositivo o subsidiario de la regulación legal hasta la desregulación de determinadas cuestiones. Esta reconfiguración del orden público laboral no se tradujo formalmente en un incremento significativo del papel regulador de la autonomía individual. Como señaló en su día la mejor doctrina, la reforma supuso «menos ley, más convenio colectivo y algo más, pero no mucho más, contrato individual» de trabajo $^{19}$. En tercer lugar, establecieron mecanismos de adaptación de la negociación colectiva, tales como las cláusulas de descuelgue salarial y la facultad del propio convenio de determinar su eficacia temporal más allá del periodo pactado.

Esta importante reforma y las muchas de diverso alcance que la precedieron dieron lugar a la primera refundición del Estatuto de los Traba-

${ }^{18}$ En este sentido ha podido afirmarse que «solo a partir de 1994, el título I ET desbloquea la concepción predominantemente "estatalista" en la ordenación del contrato de trabajo que hasta entonces había perdurado en nuestra negociación colectiva» (S. DEL REY GUANTER, «Apología introductoria...», op. cit., p. 22).

19 T. Sala Franco, La reforma del mercado..., op. cit., 1994, p. 14. 
jadores, que fue aprobada por Real Decreto Legislativo 1/1995, de 24 de marzo; texto que vino a reordenar las modificaciones operadas durante los quince años de vigencia de la norma.

La segunda gran reforma se produce en el contexto de la llamada Gran Recesión, esto es, como respuesta a las consecuencias económicas y sociales derivadas de la crisis económica 2007-2008. Una crisis que se tradujo en un grave deterioro de las principales magnitudes económicas ${ }^{20}-\mathrm{el}$ desempleo llegó en algún momento a superar el $25 \%$ de la población activa- y que, como consecuencia de nuestra integración en la Unión Económica y Monetaria europea, debía necesariamente abordarse mediante el ajuste de precios y salarios. El legislador fue muy explícito en la Exposición de Motivos de las normas que instrumentaron la reforma — primero el Real Decreto-ley 3/2012, de 10 de febrero, de Medidas Urgentes para la Reforma del Mercado Laboral, y luego la Ley 3/2012, de 6 de julio, del mismo nombre- en su diagnóstico: «La crisis económica ha puesto en evidencia la insostenibilidad del modelo laboral español. Los problemas del mercado de trabajo, lejos de ser coyunturales, son estructurales, afectan a los fundamentos mismos de nuestro modelo sociolaboral y requieren una reforma de envergadura que, pese a los cambios normativos experimentados en los últimos años, continúa siendo reclamada por todas las instituciones económicas mundiales y europeas que han analizado nuestra situación, por los mercados internacionales que contemplan la situación de nuestro mercado de trabajo con enorme desasosiego y, sobre todo, por los datos de nuestra realidad laboral, que esconden verdaderos dramas humanos».

$\mathrm{Ha}$ sido, ciertamente, una reforma intensa ${ }^{21}$ que se ha extendido a todas las secuencias de la relación laboral y a aspectos fundamentales del

${ }^{20}$ Durante los años 2008-2014, la actividad económica española se contrajo el $5 \%$ del PIB y la tasa de desempleo aumentó el $230 \%$, pues pasamos de un desempleo del 9,7\% en 2008 a otro del $22,3 \%$ en 2014. Esta contracción de la actividad económica y del empleo produjo, de una parte, una drástica disminución de la recaudación económica del Estado, que, por ejemplo, durante el trienio 2007-2009, antes de que se iniciaran las correcciones fiscales, llegó a menguar el 30\%, y una notable reducción de los ingresos por cotizaciones a la Seguridad Social, de en torno al 10\% en el periodo considerado, y, de otra, un incremento exponencial de las demandas de protección social. El gasto en prestaciones por desempleo aumentó el $88 \%$ y el gasto en pensiones el $39 \%$. El déficit público, por su parte, que en el 2008 alcanzaba el 39\% del PIB, en el 2014 supuso el 98\% del mismo. Cfr. F. PÉrEZ DE LOS CoBos ORIHUEL, «El control de constitucionalidad de la reforma laboral: principales cánones de enjuiciamiento», disponible en https://tribunalsitestorage.blob.core.windows.net/ media/14497/conferencia-dr-francisco-perez-de-los-cobos.pdf).

${ }^{21}$ Un comentario completo de la misma en J. Thibault ARANDA (dir.), La reforma laboral de 2012: nuevas perspectivas para el Derecho del Trabajo, Madrid, La Ley, 2012. Asimis- 
sistema de negociación colectiva, mas «no parece que pese a su alcance suponga una ruptura con el modelo previamente vigente, pues en general viene a abundar en líneas de reforma ya antes exploradas» ${ }^{22}$.

La relación individual de trabajo ha sido, en efecto, objeto de una profunda reforma en clave flexibilizadora que ha robustecido significativamente el poder de dirección del empresario en la relación de trabajo. Como señalaba, la reforma se ha extendido al conjunto de la regulación: se ha autorizado a las empresas de trabajo temporal a actuar como agencias de colocación; se ha modificado el régimen jurídico de los contratos formativos; se ha flexibilizado la regulación de la movilidad funcional, de la movilidad geográfica y de la modificación sustancial de las condiciones de trabajo; se han incrementado las posibilidades de distribución irregular de la jornada de trabajo; se ha suprimido la autorización administrativa requerida para llevar a cabo las reducciones de jornada y las suspensiones de los contratos de trabajo por causas empresariales, así como para los despidos colectivos, y se han reformulado en sentido liberalizador las causas de despido y se ha abaratado su coste.

Por lo que se refiere a la negociación colectiva, las reformas legales incorporadas al Estatuto han ido todas dirigidas a abrir espitas de flexibilidad en un sistema negocial rígidamente asentado sobre el convenio colectivo de eficacia normativa y general que, como hemos visto, caracteriza el sistema español de negociación colectiva. Estas vías flexibilizadoras han sido fundamentalmente tres: 1) La reformulación y ampliación de la institución conocida como «descuelgue» del convenio colectivo, esto es, la posibilidad legal ofrecida a los representantes de los trabajadores y al empresario de pactar a nivel de empresa la posibilidad de apartarse de lo establecido en el convenio colectivo que les es de aplicación cuando concurran causas económicas, técnicas, organizativas o productivas que lo justifiquen. 2) El establecimiento en la ley de una prioridad aplicativa a favor del convenio colectivo de empresa frente al de ámbito superior respecto de determinadas materias. Esta prioridad viene a incorporar a la ley la convicción del legislador de que el convenio de empresa se adapta más y mejor a las necesidades y requerimientos de la empresa y del mercado que los de cualquier otro ámbito. 3) El establecimiento de un límite máximo a la ultraactividad del convenio colectivo denunciado y no renegociado.

mo, A. Montoya Melgar y J. García Murcia (dirs.), Comentario a la reforma laboral de 2012, Pamplona, Civitas, 2012.

${ }^{22}$ J. M. Goerlich Peset (dir.), Derecho del Trabajo, 7. ed., Valencia, Tirant lo Blanch, 2019, p. 47. 
A esta segunda gran reforma legal ha seguido un nuevo texto refundido del Estatuto, aprobado por el Real Decreto Legislativo 2/2015, de 23 de octubre. De nuevo se quiso poner orden en un texto muy trasegado como consecuencia de las sucesivas e incesantes reformas.

Como hemos visto, el consenso que presidió, no sin alguna disidencia, la elaboración del Estatuto de los Trabajadores en su primera versión no ha regido la de sus dos principales reformas. Tanto la primera como la segunda fueron contestadas desde el ámbito sindical —a través incluso de la convocatoria de sendas huelgas generales- como inaceptables ataques a los derechos de los trabajadores. Las principales aportaciones de la primera pueden considerarse consolidadas en nuestro ordenamiento; por lo que respecta a la segunda, el nuevo Gobierno había anunciado solemnemente su derogación parcial y su reforma cuando la crisis del COVID-19 ha venido a cambiar dramáticamente el escenario.

\section{V. ¿HACIA UN NUEVO ESTATUTO DE LOS TRABAJADORES?}

Durante los Gobiernos de Mariano Rajoy y en las sucesivas campañas electorales celebradas desde la reforma laboral de 2012 la «derogación de la reforma laboral del Partido Popular» ha sido un leitmotiv de los partidos de izquierda. No obstante, el primer Gobierno de Pedro Sánchez, resultado del éxito de una moción de censura contra Mariano Rajoy (junio de 2018) que concitó en su contra a una muy heterogénea oposición parlamentaria, estuvo sostenido por una mayoría exigua y precaria y no pudo llevar a cabo ninguna reforma de envergadura. Las más relevantes realizadas — la restauración de la posibilidad de establecer cláusulas de jubilación forzosa en los convenios colectivos, el establecimiento de algunas medidas a favor de la igualdad de trato entre hombres y mujeres y la obligación de un registro de jornada - no afectaron a la reforma laboral del 2012 y se llevaron a cabo a través de normas de urgencia (Reales Decretosleyes 28/2018, 6/2019 y 8/2019). Este último real decreto-ley, aprobado un mes antes de las elecciones, previó en su disposición adicional primera la constitución por el Gobierno, «con anterioridad al 30 de junio de 2019, de un grupo de expertos y expertas para llevar a cabo los trabajos y estudios preparatorios de un nuevo Estatuto de los Trabajadores».

El primer Gobierno de Sánchez ha estado un largo periodo de tiempo en funciones, pues las elecciones generales celebradas casi un año después de su formación (abril de 2019) dieron como resultado un Parlamen- 
to fragmentado que no logró investir presidente del Gobierno, entre otras cosas porque Sánchez, imaginando que una nueva convocatoria electoral le favorecería, no se implicó a fondo en obtener el respaldo parlamentario que necesitaba. Durante este periodo, como resulta imaginable, nada se hizo sobre el «nuevo Estatuto de los Trabajadores» anunciado. Las siguientes elecciones, celebradas en noviembre de 2019, contrariamente a lo previsto, dieron como resultado un Parlamento todavía más fragmentado que el anterior, pero, a diferencia de entonces, el PSOE y Unidas Podemos, cuarenta y ocho horas después de conocido el resultado electoral, presentaron una «coalición de Gobierno progresista» que, recabando el apoyo de varias minorías y la abstención de algunos partidos independentistas catalanes y vascos, logró para Sánchez el pasado 7 de enero la confianza parlamentaria requerida por la Constitución. El Gobierno de coalición presentó un pacto programático («Coalición progresista. Un nuevo acuerdo para España») en el que si, de una parte, anunció reformas muy significativas de aspectos fundamentales de la reforma laboral de 2012 (derogación del despido por absentismo, de la vigente ultraactividad limitada de los convenios colectivos, de la prioridad aplicativa de los convenios colectivos de empresa, así como de reformas del régimen de las contratas, de la modificación sustancial de las condiciones de trabajo y de la regulación de los descuelgues de convenio colectivo), de otra, se comprometió a elaborar «un nuevo Estatuto de los Trabajadores del siglo XXI», previo diálogo con los agentes sociales. Una norma que debe «compaginar la protección de los trabajadores y trabajadoras frente a los desafíos sociales, tecnológicos y ecológicos del siglo XXI, y el reconocimiento de nuevos derechos de los trabajadores propios de la realidad económica, social y laboral actual, con la necesaria competitividad empresarial y el papel de la negociación colectiva como elemento de reequilibrio necesario» ${ }^{23}$. A tal efecto, se prevé que «pueda constituirse un grupo de trabajo para su redacción, integrado por expertos y expertas de reconocido prestigio del ámbito académico y profesional».

De este ambicioso programa, hasta el momento presente, en el que la crisis sanitaria, política y económica provocada por el coronavirus ha alterado todas las agendas, solo se ha llevado a cabo la derogación del despido por absentismo, una causa de despido objetivo ya contemplada en el

${ }^{23}$ La doctrina ya ha arriesgado propuestas de reforma. Vid. T. SALA Franco, Propuestas para un debate sobre la reforma laboral, Madrid, Francis Lefebre, 2018, y J. CRUZ VILLALÓN, «Hacia un nuevo Estatuto...», op. cit. 
Estatuto de 1980, cuya regulación fue flexibilizada en algún aspecto por el legislador de 2012 y que ahora ha sido eliminada de nuestro ordenamiento. Se ha dictado, eso sí, cuantiosa legislación especial de urgencia para atender a las necesidades de los trabajadores y de las empresas derivadas de la paralización de la actividad económica y el confinamiento decretados, consecuencia de la crisis del coronavirus.

El pavoroso escenario económico que se vislumbra - la actividad económica que crecía en el cuarto trimestre de 2019 al 1,8\% se ha desplomado en el primero de este año un $5,2 \%{ }^{24}$, más profundo y drástico que el que produjo la crisis de $2008^{25}$, no parece, a mi juicio, el mejor contexto para desarrollar el programa reseñado. Quizá la situación lleve al Gobierno a descubrir en la reforma de 2012, que respondió no al capricho o a una operación antilabour, como se ha dicho para demonizarla, sino a la necesidad del ajuste ante una gravísima situación económica y de desempleo, algunas virtudes que le ha negado (por ejemplo, su capacidad para generar empleo con tasas de bajo crecimiento económico). El tiempo transcurrido desde su entrada en vigor nos ofrece suficientes elementos como para saber qué medidas han funcionado para conseguir lo que en su día pretendió - la recuperación de la competitividad empresarial, la reactivación del tejido productivo y la creación de empleo-y cuáles no. En el contexto que viene, el método de ensayo/error puede ser más útil para abordar las reformas necesarias que la aplicación de recetarios ideológicos, por muy respetables que estos sean. La gravedad del horizonte que se vislumbra y la debilidad parlamentaria del Gobierno apuntan en esta misma dirección. Hoy más que nunca serían necesarios «pactos de país» para hacer frente a la envergadura de los problemas. El proceso de elaboración y tramitación parlamentaria del Estatuto de los Trabajadores de 1980 podría constituir una magnífica pauta inspiradora para el camino a recorrer.

${ }^{24}$ Cfr. «Derrumbe histórico de la economía. El PIB español se contrajo un 5,2\% en el primer trimestre, el peor desde la Guerra Civil», El País, 1 de mayo de 2020. Asimismo, E. Ontiveros, «La vulnerabilidad de España», El País, 3 de mayo de 2020.

${ }^{25}$ Los datos y previsiones disponibles son, en efecto, enormemente preocupantes. A la vista de los datos disponibles, el Banco de España augura una contracción de la economía de entre el 6 y el $13 \%$, ello podría significar que en un solo año pueda perderse más de lo que durante la Gran Recesión se perdió en seis. El paro alcanza ya la cota del 14,5\% y se prevé que la deuda española alcance el $120 \%$ del PIB a finales de 2020. Cfr. J. C. DíEZ, «Deuda pública al 120\% del PIB», El País, 1 de mayo de 2020. 


\section{BIBLIOGRAFÍA}

Borrajo Dacruz, E.: «Los convenios colectivos en el nuevo marco de las relaciones laborales (una introducción al Estatuto de los Trabajadores)», Revista de Estudios Sociales, núm. 1 (1979), pp. 37 y ss.

Casas BaAmonde, M. E.: «La significación principal del Estatuto de los Trabajadores en el ordenamiento laboral constitucional», Trabajo y Derecho, núm. 63 (2020).

Cabero Morán, E.: «La Ley del Estatuto de los Trabajadores cumple cuarenta años con tres versiones (1980, 1995 y 2015) y más de setenta reformas», Trabajo y Derecho, núm. 63 (2020).

Cruz Villalón, J.: «Hacia un nuevo Estatuto de los Trabajadores», Trabajo y Derecho, núm. 63 (2020).

Del Rey Guanter, S.: «Apología introductoria de la ley del estatuto de los trabajadores», en S. Del Rey Guanter (dir.), Estatuto de los Trabajadores. Comentado y con jurisprudencia, Madrid, La Ley, 2005, pp. 23-36.

Díez, J. C., «Deuda pública al 120\% del PIB», El País, 1 de mayo de 2020.

Goerlich Peset, J. M. (dir.): Derecho del Trabajo, 7. a ed., Valencia, Tirant lo Blanch, 2019.

Montoya Melgar, A.: «La Ley 43/2006 en el marco de las reformas laborales», en A. Montoya Melgar, J. M. Galiana Moreno, F. Cavas Martínez y A. Cámara Bоті́A, Comentario a la reforma laboral de 2006, Madrid, Civitas, 2007.

Montoya Melgar, A., y García Murcia, J. (dirs.): Comentario a la reforma laboral de 2012, Pamplona, Civitas, 2012.

NAPOLI, M.: «Lo Statuto dei lavoratori ha quarant'anni, ben portati», Lavoro e diritto, núm. 1 (2010), pp. 123-138.

Ontiveros, E.: «La vulnerabilidad de España», El País, 3 de mayo de 2020.

Palomeque López, M. C.: «Estatuto de los Trabajadores», en AAVV, Enciclopedia Laboral Básica «Alfredo Montoya Melgar», Madrid, Civitas, 2009.

Pérez de los Cobos Orinuel, F.: «El control de constitucionalidad de la reforma laboral: principales cánones de enjuiciamiento», disponible en https://tribunal sitestorage.blob.core.windows.net/media/14497/conferencia-dr-francisco-perez-de -los-cobos.pdf.

Romagnoli, U.: Il lavoro in Italia. Un giurista racconta, Bolonia, Il Mulino, 1995.

— «Tornare allo Statuto», Lavoro e diritto, núm. 1 (2010), pp. 39-48.

Sagardoy Bengoechea, J. A.: «Pre e intrahistoria del Estatuto de los Trabajadores», Revista Española de Derecho del Trabajo, núm. 100 (2000), pp. 19-35.

Sala Franco, T.: La reforma del mercado de trabajo, Valencia, CISS, 1994.

- Propuestas para un debate sobre la reforma laboral, Madrid, Francis Lefebvre, 2018. 
SuÁREz GonzÁLEz, F.: Las nuevas relaciones laborales y la Ley del Estatuto de los Trabajadores, Madrid, Pirámide, 1980.

Thibault ARAnda, J. (dir.): La reforma laboral de 2012: nuevas perspectivas para el Derecho del Trabajo, Madrid, La Ley, 2012.

VIDa Soria, J.: «Vilanos del Estatuto de los Trabajadores (sobre su génesis, significado, evolución y su desaparición)», en J. M. GoerLich Peset (coord.), Comentarios al Estatuto de los Trabajadores. Libro bomenaje a Tomás Sala Franco, Valencia, Tirant lo Blanch, 2016, pp. 33-40.

Zoppoli, L.: «Le rughe dello Statuti e le maschere del futuro», Lavoro e diritto, núm. 1 (2010), pp. 59-73. 